\title{
(息)
}

Citation:

Stevens, RC and Raybould, D (2015) The reality paradox: Authenticity, fidelity, and the real in Battlefield 4. The Soundtrack, 8 (1-2). 57 - 75. ISSN 1751-4207 DOI: https://doi.org/10.1386/st.8.1-2.57_1

Link to Leeds Beckett Repository record:

https://eprints.leedsbeckett.ac.uk/id/eprint/2216/

Document Version:

Article (Accepted Version)

The aim of the Leeds Beckett Repository is to provide open access to our research, as required by funder policies and permitted by publishers and copyright law.

The Leeds Beckett repository holds a wide range of publications, each of which has been checked for copyright and the relevant embargo period has been applied by the Research Services team.

We operate on a standard take-down policy. If you are the author or publisher of an output and you would like it removed from the repository, please contact us and we will investigate on a case-by-case basis.

Each thesis in the repository has been cleared where necessary by the author for third party copyright. If you would like a thesis to be removed from the repository or believe there is an issue with copyright, please contact us on openaccess@leedsbeckett.ac.uk and we will investigate on a case-by-case basis. 


\section{The Reality Paradox: Authenticity, fidelity and the real in Battlefield 4}

\section{Richard Stevens and Dave Raybould, with additional contributions from Ben Minto, Audio Director} Battlefield $4 .^{1}$

Although the interactive medium of video games is often referred to as non-linear, since progression through the game may follow different paths on repeated playthroughs, it is typically much more linear than the medium of film with respect to its treatment of time and space. The grammar of film involves frequent cuts between perspectives, geographical locations and times, whereas, for example, military first person shooter games much more closely match the perceptual experience of everyday life through their spatial and temporal continuity. It is not surprising, then, that this game genre often aspires to simulate the reality of the physical world (Gapper, 2014) based on an assumption that the construction of a 'believable, realistic space' will be a significant driver for players' immersion in the game (Collins, 2008). Indeed, the trailer to Battlefield 3 (Electronic Arts, 2011a) posited the question 'Is it real? Or is it Battlefield 3?' (Electronic Arts, 2011b). ${ }^{2}$

This paper will examine how the Battlefield series of games facilitates player immersion ${ }^{3}$ in the game world by appropriating audio characteristics from our typically mediated experience of conflict and through a meticulous approach to modeling an authentic real-world audio experience. The paper also discusses how we might reconcile this immersion in the seemingly real and authentic with the presence of the more artificial or inauthentic ludic elements of the soundtrack required to support gameplay.

\section{Authenticity in ambience}

An attempt to clarify problematic terms such as "real" and "authentic" forms part of the discussion below but such notions should be seen within the context of Michel Chion's point that realism does not necessarily equate to reality. In games, as in cinema, the audio-visual channel needs to transmit or render an experience that in the physical world is perceived by many senses. In order to more convincingly relate the "real" experience, aspects of the audio-visual representation of real-world phenomena will often be heightened or manipulated (Chion, 1994). We will return to a specific usage of "real" below but for the moment we will adopt "authentic" to indicate audio that players might consider credible for the real-world circumstance represented by the game.

The ambient sounds in Battlefield 4 (Electronic Arts, 2013) are generated through a combination of "Sound Areas" - up to thirty multi-layered quadraphonic loops of approximately three minutes length per level (Figure 1), "Big World" sounds - one-shot identifier sounds such as animals, insects, and distant war, which are randomly triggered and randomly positioned, and "Spot Sounds" which are placed at specific locations within the game (Figure 2 ). ${ }^{4}$

\footnotetext{
${ }^{1}$ Personal correspondence between the authors and Ben Minto is indicated by the reference (Minto, 2014).

${ }^{2}$ The discussion of systems for the implementation of audio in Battlefield 4 discussed below has been simplified for more general consumption and so should be taken as a general indication of the approach - rather than an absolute description of every detail.

${ }^{3}$ Although there is a wide variety of literature on types of immersion (Ermi and Mäyrä, 2005), presence (Ryan, 2006; Skalski and Whitbred, 2010) or incorporation (Calleja, 2011) it is perhaps most useful, in the absence of any unifying theory at this stage, to consider it as an umbrella term (Nacke, 2011) for a phenomenon that operates on a continuum of involvement (classified by Brown and Cairns as ranging from engagement through engrossment to total immersion [Brown and Cairns, 2004]), and that immersion is not a type, but a state which can be instigated and supported through a range of different processes or drivers.

4 “Sound Areas", "Big World” sounds and "Spot Sounds” are terms that were used by designers for Battlefield 4.
} 

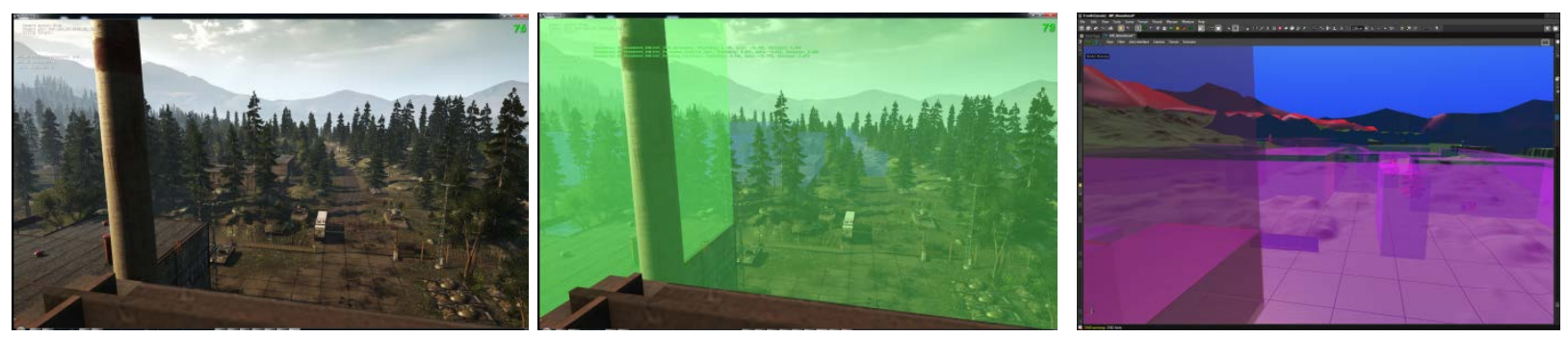

Figure 1: Game view, Active Sound Areas, All Sound areas. (Courtesy of DICE Electronic Arts, 2014)

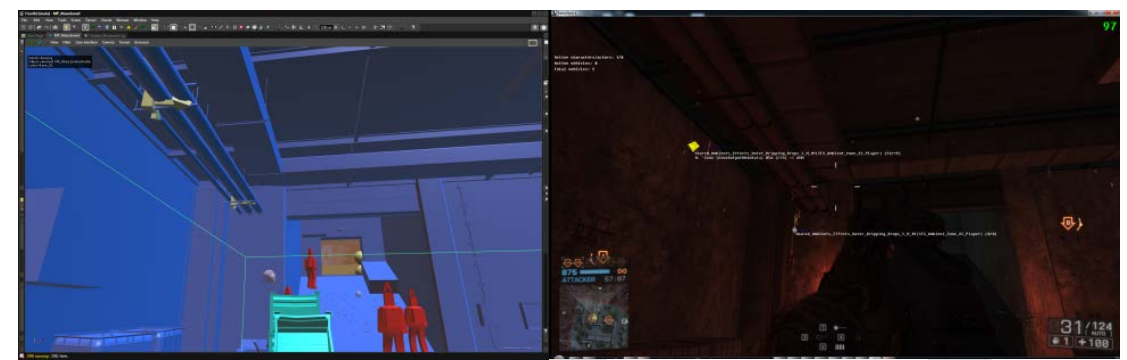

Figure 2: 'Spot Sounds' in the editor and debug view. (Courtesy of DICE Electronic Arts, 2014)

Forming part of the acoustic ecology of the game (Grimshaw, 2007), each of these elements for the seven main locations (each containing over 100 unique sub-areas) in the single player campaign for Battlefield 4 , has been meticulously researched to reflect what Schafer might refer to as the Keynote sounds (the background environmental sounds) and Soundmarks (sonic landmarks) of their real world counterparts (Schafer, 1994), even to the extent of reflecting the appropriate season during which the action takes place, as Mari Saastamoinen Minto explains: ${ }^{5}$

For Caspian Border in Battlefield 3, we used sounds from swallows that exist in the real Caspian area. But in Second Assault (Battlefield 4 expansion released November 2013) it's autumn, so we want birds with a more autumn-like sound. We've found a bird called Caspian Snowcook, but we've already used that in the Alborz Mountain map, so the bird hunt goes on... (Saastamoinen Minto, 2013)

\section{Authenticity in Foley}

For the player to feel a sense of perceptual presence within the environment it is also important that the sounds that are generated as they interact with it (referred to by Grimshaw [2010] as kinediegetic sounds) match with the player's sonic expectations that have been formed in the physical world. Indeed, some consider this ergo-audition (Chion, 2010), the 'perception and joy of self-generated sounds' (Leibe, 2013), to be key to enhancing the player's sense of presence, by extending the body into the game (Collins, 2011). In order to feel authentic, the sounds must match the depiction of movements (or achieve 'kinesonic congruence' [Collins, 2013]) and avoid any sense of repetition; a key challenge to the game sound designer is avoiding the repeated soundfile, a disruptor of immersion (Vachon, 2009). To combat this problem of repetition in Foley sound, Battlefield 4 uses three categories of footstep samples (walk, run, and sprint) for each of the basic surface types (dirt, tarmac, wet tarmac, wood, grass short, grass long, gravel, metal, sand, water, forest, snow, ice, glass, and indoor floor). These footstep sounds are not played as discrete samples, but are blended with each other depending on the speed at which the playercontrolled character moves through the environment (which modulates the amplitude and duration of the

\footnotetext{
${ }^{5}$ See accompanying video 01: “Ambience”.
} 
sound). They are further varied via a random pitch shift. The footsteps are supplemented by a Foley layer from the character's clothing, which again uses blending techniques, modulating both the amplitude and pitch using player speed across the different movement types. Each of these types of movement (walk, run, sprint, scuffle, crawl, vault, land, change pose, fall, swim, and melee) also have associated samples within their own logic systems, generating a Foley system of huge complexity and flexibility (Figure 3). ${ }^{6}$

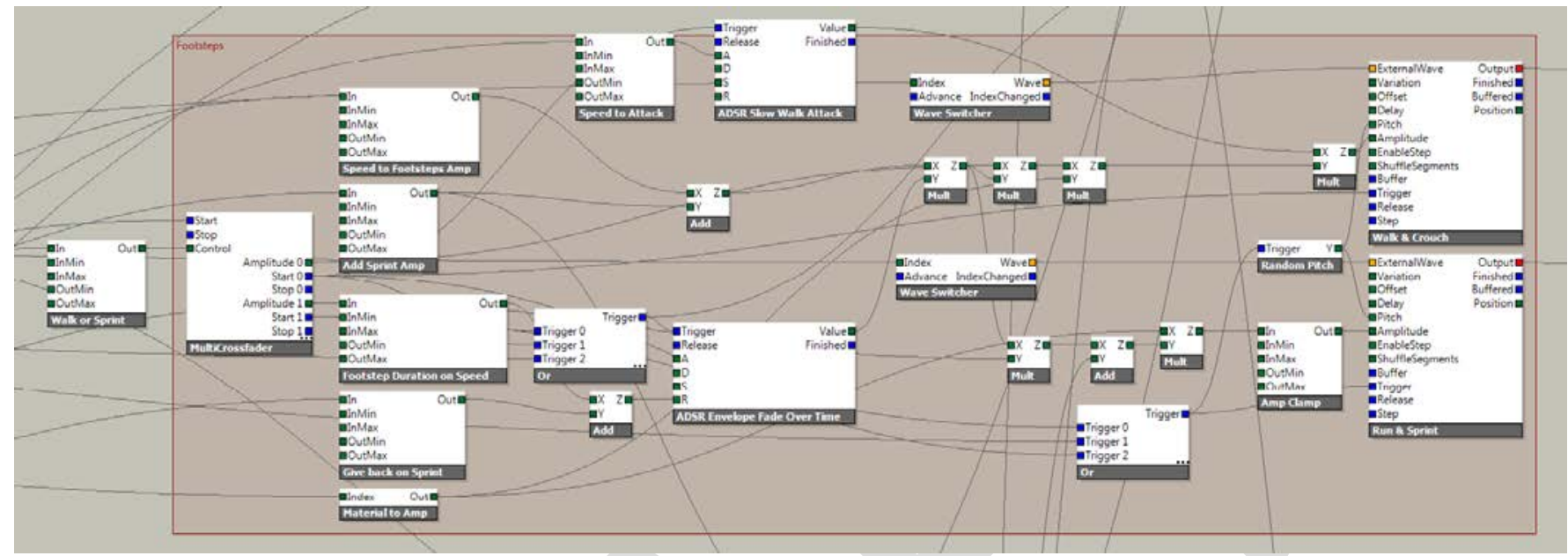

Figure 3: One of 16 Foley subsystems. (Courtesy of DICE Electronic Arts, 2014)

The importance of the role of Foley for player immersion is recognized by the decision in Battlefield 4 to remove them from the automated mixing system so that they are always present in the mix.

...whilst your firearm is the key way you interact with the environment, you have a big part to play too, so we've taken player Foley out of the High Dynamic Range mixing system, now explosions will not cull your footsteps; there's a constant sonic connection between character and world. (Minto in Broomhall, 2013)

\section{Authenticity of acoustics}

Just as sound adds materiality to visual objects (Beck, 2008), giving the two dimensional images weight and substance, the acoustic reverberation within a game adds materiality to the graphical renderings of the environment. The sheer complexity of calculating the scattering of sound waves across an intricate virtual scene remains out of reach of the real-time demands of video games ${ }^{7}$ so the items of key importance in the shooter game, the weapons, rely on a system of pre-rendered sounds to evoke the acoustic response of the different spaces within the game.

In Battlefield 4 each weapon sound is in fact a combination of numerous elements. These enable the player to identify the weapon type (the 'What?') through the transient ${ }^{8}$ and body elements of the sound, and create a sense of authenticity for the game environment (the 'Where?') through additional layers and reverb tails (Minto, 2011).

\footnotetext{
${ }^{6}$ See accompanying video 02: "Foley".

${ }^{7}$ Attempts to pre-compute an accurate impulse response to convolve in real time would require 60GB of data per $\mathrm{M}^{3}$ (Raghuvanshi et al., 2010).

${ }^{8}$ The initial attack portion of the sound.
} 


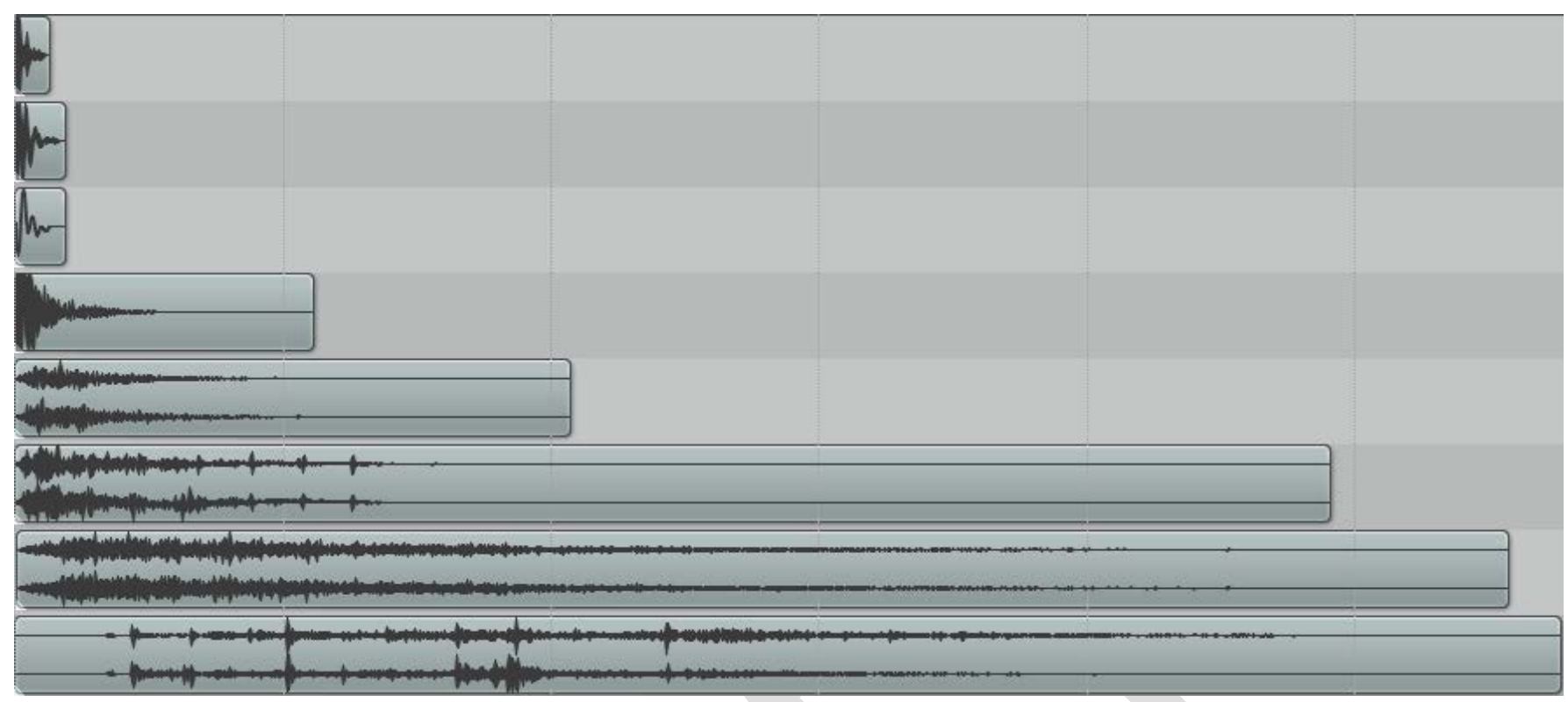

Figure 4: Weapon layers (for illustration only).

In Figure 4, the top three files represent the "body” elements of the weapon and the five lower audio files are the pre-recorded acoustic tails captured to represent environments such as 'Indoor Small', 'Indoor Large', 'Urban', 'Far', and 'Open field'. ${ }^{9}$ There are multiple variations for each tail type, and the blending between the different types is governed by run-time parameters based on the type of area in which the weapon sounds. ${ }^{10}$

Although we have touched only briefly on some of the systems within the game, we can see how the Battlefield audio team go to great lengths to achieve authenticity in the audio through the appropriation of realistic ambiences, Foley and acoustic spaces.

\section{Authenticity through codes of realism}

Although some of us will be conscious of 'the symbol, the emblematic sound(s)' (Chion, 2009) that serve as codes of reality in cinema, such as the lonely Amtrak horn that echoes through every wrong-side-ofthe-tracks neighborhood, or the Kookaburra laugh that embeds the truth of a jungle environment (despite actually being native to Eastern Australia), much less explored is the role played by the quality and characteristics of the medium itself in informing our notions of the authentic. What is considered authentic is actually an evolving notion that is based on the fidelity of the recording and storage mediums available in a particular era or context. In visual terms we are very familiar with how the distortions of dust and scratches over black and white imagery, or the aspect ratio and grain of 1980s home video can be used to reference different eras or contexts. Likewise, when assessing whether the Battlefield series has achieved its aims of creating a 'real and believable world' (Strandberg in Jock, 2011), we bring our expectations formed by mediated realism to play. In the Battlefield series we can trace this influence, from the DV Cam of television news and documentary footage to the vérité rawness of the new media of citizen journalism such as the mobile phone and personal camera.

\footnotetext{
${ }^{9}$ See accompanying video 03: "Weapons”.

${ }^{10}$ The description and illustration of the weapons system here is illustrative since the actual system is far too complex to tackle in this paper.
} 
Each [game] release is like an audio snapshot of the time. Bad Company was as recorded through a handycam mic. Bad Company 2 was akin to mobile phone recordings uploaded to YouTube. For Battlefield 3, the 'unedited war' vibe of contemporary Iraq and Afghanistan documentaries was the benchmark, resulting in a more refined and decipherable soundscape for the game. For Battlefield 4 we wanted to recapture the rawness of BC2 [Bad Company 2], but not at the expense of clarity and readability.....This is the "Go-Pro helmet-mounted camera" take. (Minto in Broomhall, 2013).

Throughout the development of previous Battlefield games, the aesthetic of the authentic has often led to a preference for the characteristic artifacts produced by consumer level (i.e. "lo-fi") audio equipment for the sounds of battle.

When we were recording military exercises, it was the crappiest recorders capturing the most violent sound that actually ended up in the game not the expensive recorders - they sound more "authentic" when compared to the kind of war footage we're used to seeing. (Strandberg, 2011) ${ }^{11}$

Or as Audio Director Ben Minto puts it, 'we don't mind recordings with dirty in them - embrace the dirt' (Minto, 2014).

In Battlefield 4 we can identify specific examples of these types of distortions or colorations, such as the buffeting of wind against the microphone (specifically in the coastal storm of the 'Singapore' level) (see Figure 5) or the clipped distorted recordings produced by signal overload (see Figure 6), most apparent in the tank projectile impact sounds in 'Shanghai', and the optional 'War Tapes' audio setting (introduced in Battlefield: Bad Company 2) that 'mimics the very heavy compressed and distorted feel of video footage recorded out in the field.. it's an aesthetic setting that embraces or translates the game sound into the "sound of youtube-ism" where everything is exaggerated. It's like a film-grain filter in Photoshop' (Strandberg in Jock, 2011) (see Figure 7). ${ }^{12}$

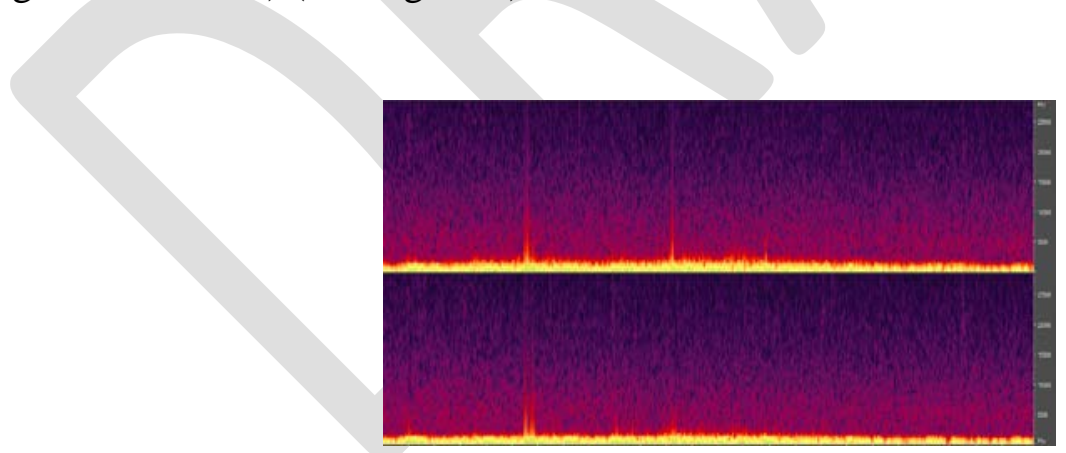

Figure 5: High levels of low frequency energy caused by air turbulence moving the diaphragm of the microphone wind buffeting.

\footnotetext{
${ }^{11}$ In the DICE weapon recording video (https://vimeo.com/20869893) compare the sound of the recording made with the DPA4011 (approximately £1,500) and HHB Portadrive (approx. £8,000) to the one made by the Zoom H2 (approx £100).

12 See accompanying video 04: "Medium Distortions".
} 


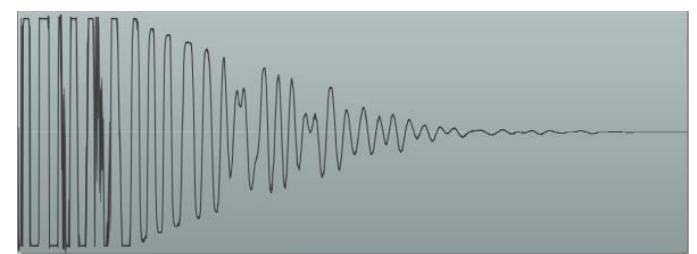

Figure 6: The clipped waveform of a tank projectile impact sound.

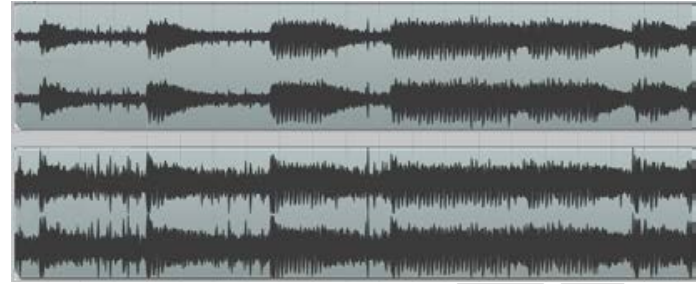

Figure 7: The heavily compressed results of the "War Tapes" setting.

A now commonly used term in game audio, the HDR (High Dynamic Range) mixing system mentioned above was originally developed by DICE (Digital Illusions CE) in 2006 as a way of ensuring certain mix priorities through an automated process, mapping the large dynamic range of reality onto the smaller one permitted by 16-bit playback systems (140dB to 96dB [Huber and Runstein, 2010]). ${ }^{13}$

HDR preserves the relative assigned $\mathrm{dB}$ difference between adjacent sounds within a fixed, yet movable, window of dynamic range. The window will always rise to encompass the loudest sounds, and those that fall below the minimum threshold are culled away. (Minto, 2014)

In addition to this automated application, the HDR system is also exploited creatively within Battlefield 4 as a symbol for loudness itself. Instead of trying to recreate the true dynamic range of war (neither possible nor desirable since machine gun fire in an enclosed space would lead very quickly to permanent hearing loss), the "pumping" effect of cheap limiters found in consumer video equipment (where the recording volume is automatically lowered to avoid clipping distortion, once a peak threshold is reached, before gradually resetting) is adopted as a metaphor for the amount of acoustic energy put into an environment, and the environment's recovery from this audio assault.

Loud is not just about volume - but perceived effect on the environment. HDR pumping can be set per level, it's basically the release time which can be varied across a level - i.e. after something loud, how quick do the quiet sounds come back? It can also have a cumulative effect, so if you fire for longer it takes longer for the energy to disperse and allow quiet sounds back. We choose to exaggerate the effect in some cases in the BF titles - it makes loud things feel louder/brutal. (Minto, 2014) ${ }^{14}$

\footnotetext{
${ }^{13}$ Menu options allow the player to target a range of playback systems, from the relatively narrow dynamic range for TV speakers to a more filmic range for Hi Fi or home cinema setups (Minto, 2011).

${ }^{14}$ See the "Shanghai" section of accompanying video 02 for an illustration.
} 


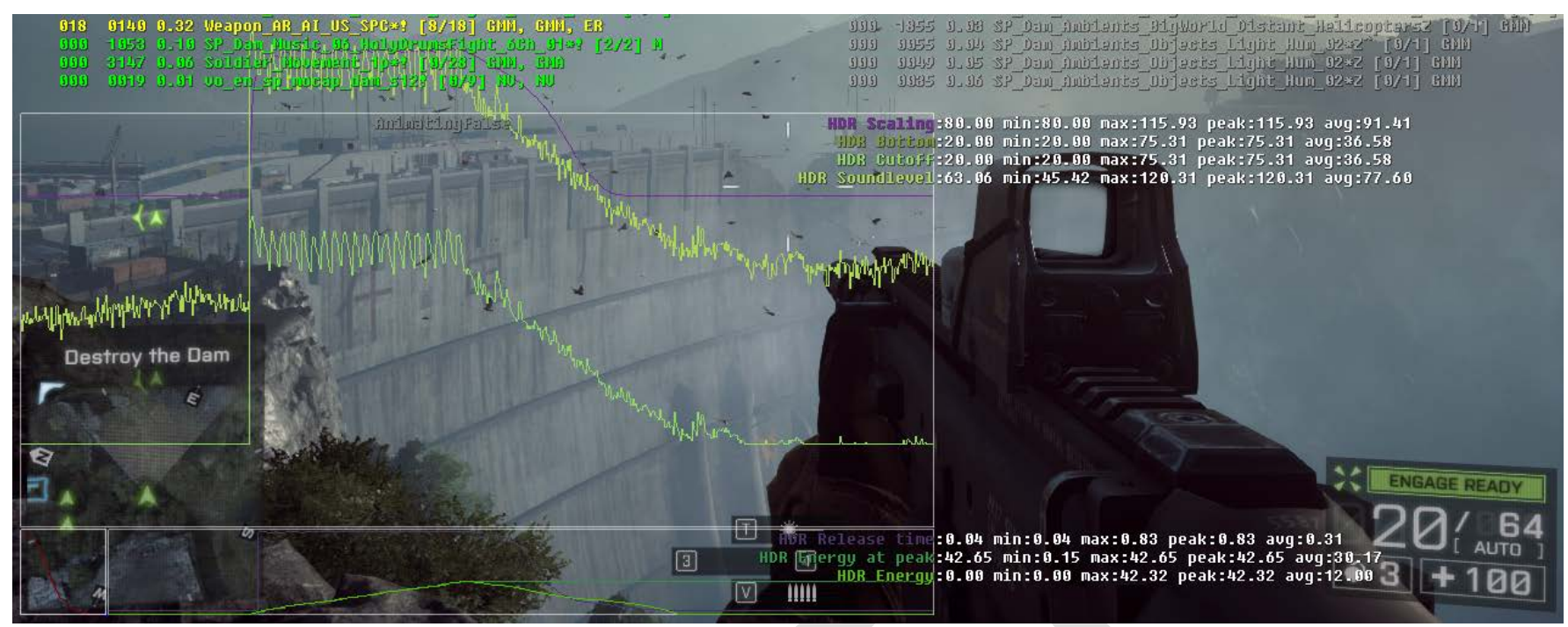

Figure 8: HDR response: ambience, weapon firing, then HDR release. (Courtesy of DICE Electronic Arts, 2014)

It can be seen in Figure 8 that the HDR level returns to is base setting of 80, after reaching a peak of 115.93 (see HDR Scaling data in Figure 8 above) but it does so over a "release” time period, the resultant gradual re-introduction of the quieter sounds evoking the pumping effect of consumer audio equipment. ${ }^{15}$

\section{The paradox of the "inauthentic"}

As described above, Battlefield 4 invests significant resources to immerse players in a realistic ambient environment and to support their sense of presence in the game through realistic interaction sounds (Foley) and acoustic responses. We could describe such sounds as "real", in that they are representations or attempted simulations of audio in the physical world (bearing in mind the caveat regarding rendering made in the opening comments). The reality signifiers that reference distortions of recording or reproduction media (such as buffeting, clipping, compression, and pumping) are clearly not "real" in the same way, but can be instead described as "mediated real"16 in that they still match a player's expectations or schema and therefore feel "authentic". In other words the "authentic" encompasses both the "real" and the "mediated real".

Through the construction of a seemingly authentic soundtrack, Battlefield 4 is more successful than most in evoking the perceived reality of being in combat (as a number of military veterans have testified [Beynon, 2013]) and yet it appears a paradox that, on close inspection, a significant proportion of the audio appears to make no attempt to be authentic (neither "real” nor "mediated real”) at all.

\section{Identifying the "inauthentic"}

Below are some of the sounds present in the game that appear to have no basis in the reality of the game world. $^{17}$

1. As the mission instructions appear on the screen they are accompanied by electronic sounds (Figure 9).

\footnotetext{
${ }^{15}$ These numbers are for illustration only, the precise nature of the numbers and functioning of the system is not in the public domain.

${ }^{16}$ It has been noted before how immersion in games often derives from a 'cinematic realism' rather than an objective one (Collins, 2008:

134) but it is perhaps useful to extend this concept to "mediated realism".

${ }^{17}$ See accompanying video 05: “ego-ludic sounds”.
} 


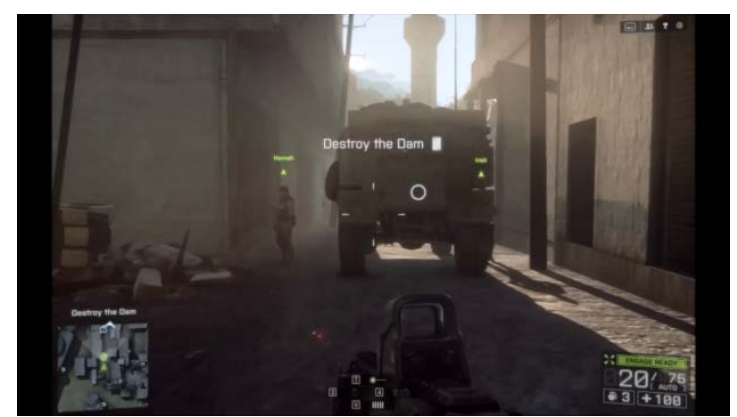

Figure 9: Mission instructions.

2. As the player approaches an enemy, a synthesized sound accompanies the appearance of a semicircular indicator on the screen, orientated in the direction of the enemy (Figure 10). This intensifies in volume, notifying the player of the enemy’s increasing awareness of their presence.

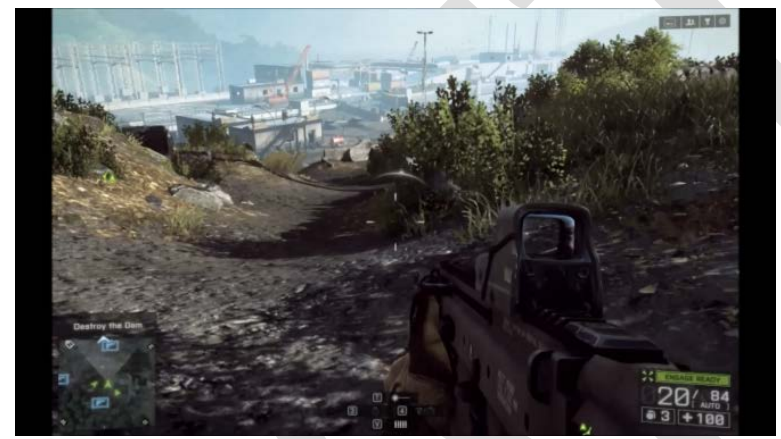

Figure 8: Icon indicating the enemy's awareness of the player.

3. When coming within a certain radius of a collectable item, a sound plays as an orientation function, alerting the player to its close proximity. Another sound notifies the player of a successful pickup. (Figure 11) (The automatic picking up of ammo is also accompanied by a reload notification sound.)

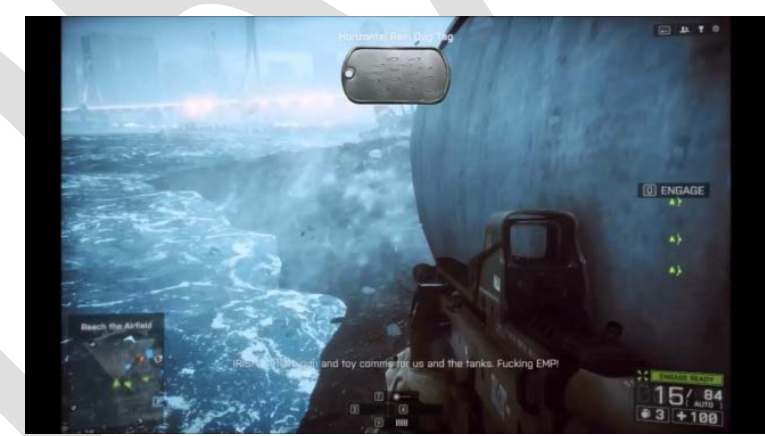

Figure 9: Item pickup.

4. A sound notifies the player that their squad is available and awaiting instruction, and then another accompanies the appearance of orange aiming reticles as confirmation feedback that the command has been received from the player (Figure 12). (A charging up and breath sound also serves as notification when the player's health rejuvenates to full). 


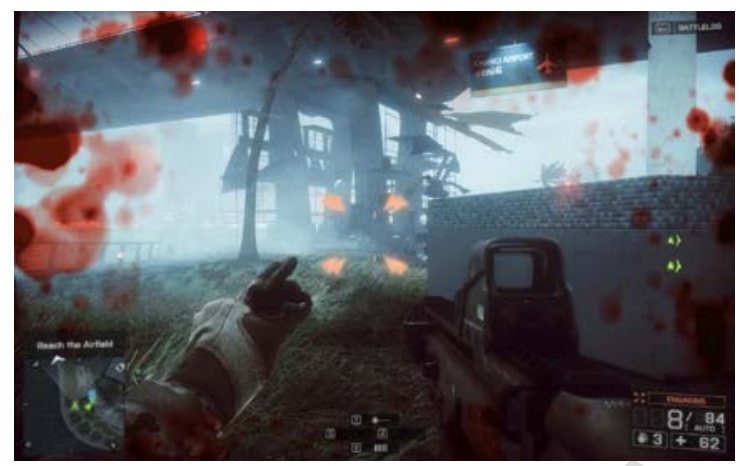

Figure 10: Squad accepts instructions.

Unlike the authentically "real” sounds of ambience, Foley, and weapons discussed above, where every effort is made to match the variation in sound found in the physical world, these sounds appear to share a different characteristic, in that they are all highly repetitive. Even if exactly the same sound is not always repeated (though it is in most cases), then at least they are repetitive in gesture, using four or five highly related sounds, as in the instance of the ammo pickup notifications.

\section{Ludic functions of the "inauthentic"}

What also unites these inauthentic (or "unreal”) sounds is that they are all performing a ludic function, that is, they are all supporting the player's ability to succeed in the game by providing vital gameplay information (Stevens and Raybould, 2014). Much of the "fun” of games derives from the player's fundamental desire for mastery (Przybylski et al., 2010) and the sense of immersion that comes from engaging with challenge (Ermi and Mäyrä, 2005), but in order to maintain the player's state of flow (Csíkszentmihályi and Csíkszentmihályi, 1992), the player’s skills must remain balanced against the challenges they face. The function of these sounds in drawing attention to instructions, providing notification, feedback, and orientation to the player are vital in compensating for the relatively low fidelity of information available when playing a game, when compared to that of the physical world.

The SALIs (State And Location Indicators, see Figure 13), such as the direction indicators referred to above under 2., provide a good example of the issues at play here. These semicircular icons, which have become part of the grammar of games through their ubiquitous adoption in first and third person genres, perform the dual function of informing the player about the current state of the enemy (since due to resolution and memory issues we often lack the graphical fidelity (Figure 14) that might allow us to represent the non-playable character's (NPC's) emotional state through facial expression or body language [Edsall, 2003]) and the off-screen direction of the enemy - the field of view in Battlefield, like most first person games is limited to around 60-70 degrees (Saastamoinen Minto, 2013).
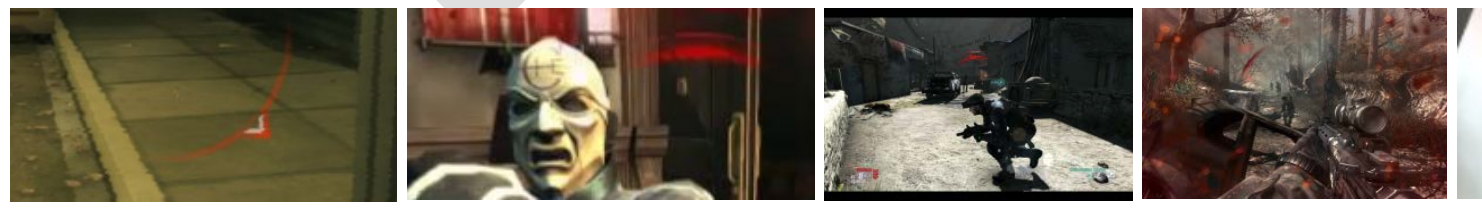

Figure 11: The ubiquity of State And Location Indicators (SALIs): Deus Ex: Human Revolution (Eidos, 2011), Dishonored (IO Interactive, 2012), Splinter Cell: Blacklist (Ubisoft, 2013), Call of Duty: Ghosts (Activision, 2013), Far Cry 3 (Ubisoft, 2012). 

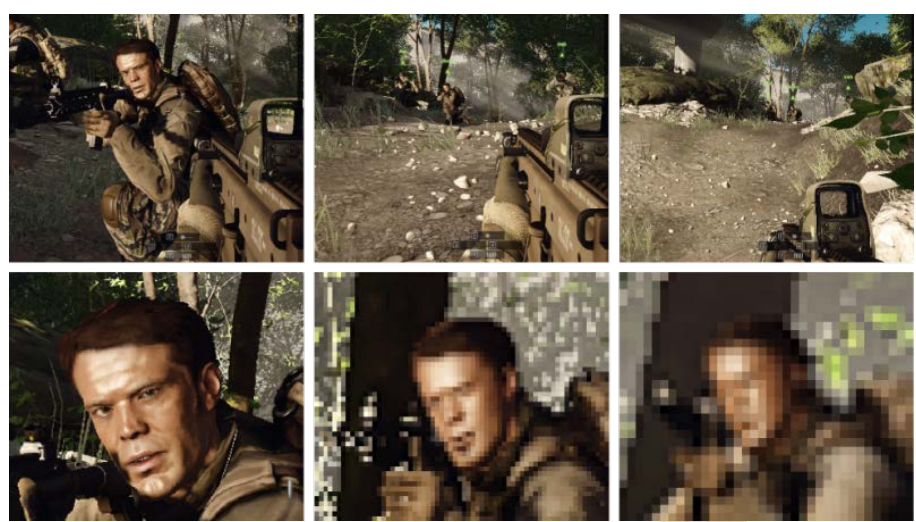

Figure 12: Illustration of the lack of fidelity in facial expression when viewed over distance in Battlefield 4.

The proximity cue for collectables (group 3, above) is also a compensation for limited graphical fidelity and field of view, and confirmation sounds for the pickup of collectables or the acknowledgement of squad instructions (group 4) are a proxy for the haptic feedback that would provide a confirmation of interaction in the physical world (Stevens and Raybould, 2011). Although they could be perceived as inauthentic, these ludic functions of audio convey vital information to the player. As Ben Minto describes, '...the more information [players] have the more informed their choices and the more immersive the title becomes. If the choices pay off they feel the game is “better”.' (Minto, 2014)

\section{Situating the "authentic" and "inauthentic"}

Of course, many of the "authentic” elements of a game's soundtrack also provide ludic information. Experienced players can decode the high frequency content of a machine gun sound to understand its distance from them, or identify the particular faction that the sniper on the distant horizon belongs to through the characteristic crack of the rifle. The iconic, repetitive sound signals of the purely ludic, however, appear to occupy a specific place within a game's social and functional space. The concepts of diegesis have been seen to be problematic for film (Kassabian, 2013), and even more so for games (Jørgensen, 2011), so firstly we will attempt to position these sounds within a self-devised framework that is focused on the function of the sound, and by whom it is heard (Figure 15). 


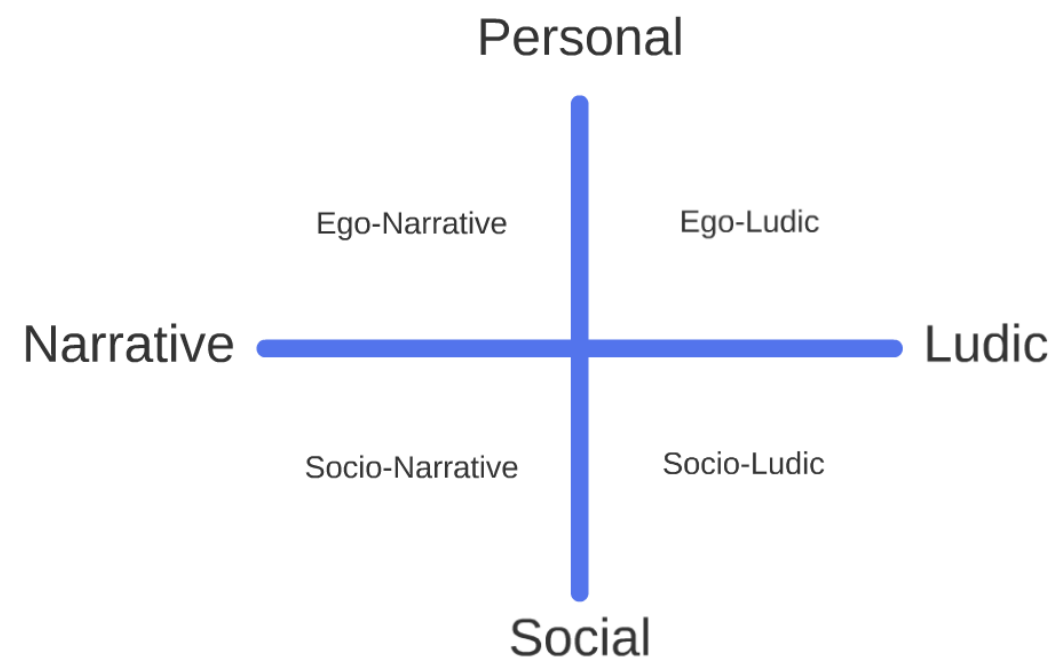

Figure 13: The functional spaces of game audio. (The lines are not ones of division but are purely for orientation.)

1. Narrative: Audio that draws us into a fictional world or narrative.

2. Ludic: Audio that provides information to help the player achieve, or motivate the player towards achieving, mastery.

3. Social: Audio that is heard by all agents/entities in the game.

4. Personal: Audio that is heard only by the player.

It is clear that many games contain both strongly narrative elements and ludic elements (Aarseth, 2004), and the relative proportions of these vary significantly with genre. For example, a platform game such as Super Mario Bros. (Nintendo, 1985) might be strongly ludic, with much of the content being about feedback and reward, and the idea of a narrative, or narrative world, being questionable in terms of its impact on the experience of play. In contrast, a role-playing game such as Skyrim (Bethesda Softworks, 2011) will have far fewer of these elements, instead being focused on the socio-narrative depiction of a credible world.

Battlefield contains elements from all functional zones; the ambient sounds (socio-narrative), voice-overtype instructional speech directed at the player from their fictional superiors (ego-narrative), playergenerated sounds (such as footsteps) that serve a ludic function to others in alerting them to the player's location (socio-ludic), and of course, the instructional, notification, feedback, and orientation sounds referred to above, which are heard only by the player, and which we can now identify as being "egoludic” (Figure 16). 


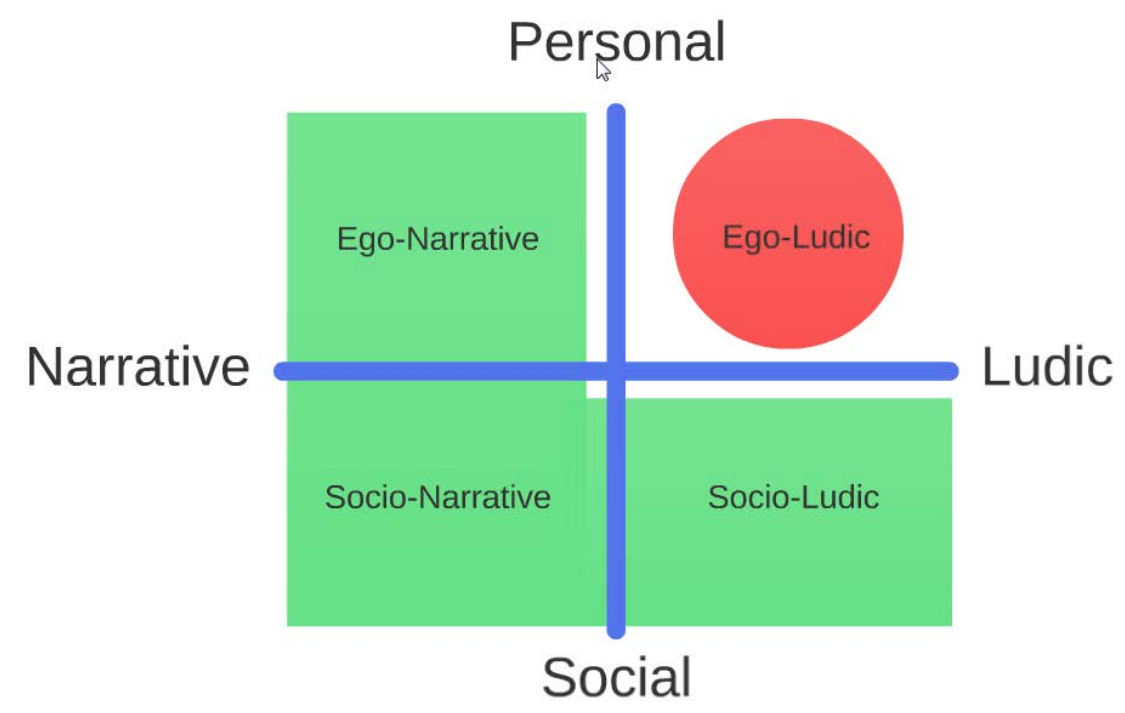

Figure 14: The "real" and the "unreal".

It is these repetitive, highly encoded, elements which clearly fall outside of the representation of the authentic in Battlefield 4, and indeed it could be said that the aesthetic of video game audio is the product not only of technological constraints (Collins, 2008) but of ludic imperative; it is the presence of the egoludic that makes games sound like games.

These sounds appear to occupy a space similar to that of the visual Heads Up Display (HUD) present in many games, in that they are clearly part of the game, and yet distinct from the reality of the game world (Figure 17). It has been seen that, despite this apparent disconnect, the presence of HUDs does not have a discernable effect on a player’s sense of immersion (Jørgensen, 2012), and in many cases the attempts to better integrate them into the narrative world or provide some justification for their presence are unnecessary (Fagenholt, 2009). In this light, the old diegetic considerations of defining elements in relation to them being internal or external to the game-world makes little sense, since ego-ludic audio and Heads Up Displays are clearly part of the game, and therefore internal or diegetic, and if everything is diegetic then the terminology becomes redundant. ${ }^{18}$
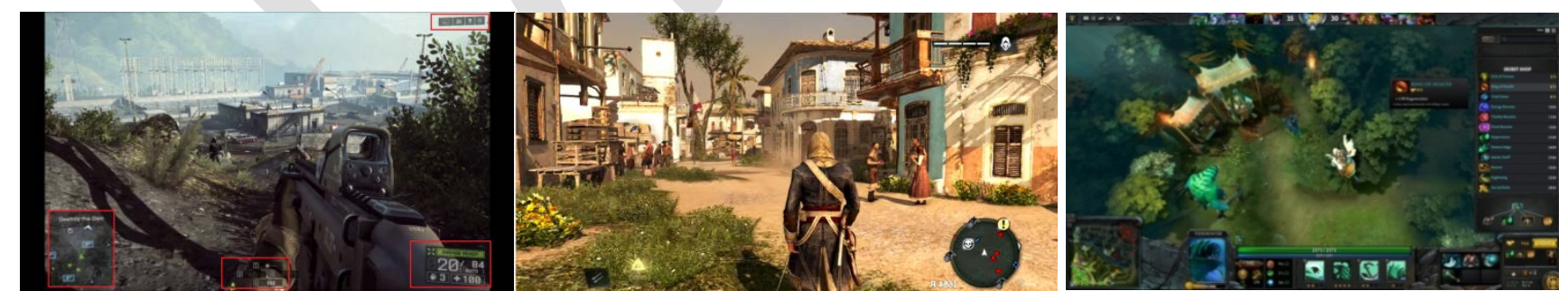

Figure 15: HUDs (Heads Up Displays) from BF4, Assassin's Creed IV: Black Flag (Ubisoft, 2013), DOTA2 (Valve, 2013).

Explaining, understanding or resolving the paradox of the "authentic" and "inauthentic" This discussion of social-functional spaces in games helps us to categorize, define and identify the authentic ("real” and "mediated real”) and inauthentic, but does not bring us any closer to explaining how

\footnotetext{
${ }^{18}$ This point is articulated more fully from an interface perspective by Jørgensen (2014).
} 
these seemingly contradictory elements can co-exist in Battlefield without affecting a player's absorption in the game. How do we explain the fact that 'even in the presence of non-authentic sounds....game players experience immersion’ (Grimshaw, 2012)?

If we have a reality schema, ${ }^{19}$ formed through our everyday experience (and our mediated experience), then it follows that as our familiarity with gaming grows (our 'ludoliteracy' develops [Poulsen and Gatzidis, 2010]) we also develop a gaming schema, one that is conversant with the tropes and expectations of the medium, so part of the acceptance of the incongruence of the ego-ludic within an authentic soundscape is simply down to our learnt experience of games. Indeed it could be that, for people unfamiliar with the medium, it is precisely these kinds of repetitive sounds, seemingly not embedded in the narrative world of the game, that prove to be disruptive to immersion. For the gamer, however, once they understand the encoded meaning of the sound, they no longer actively listen to the sound in the same way, they simply register its meaning and its implications for gameplay. In order for this to happen, the positioning of a particular sound as ego-ludic needs to be clear; i.e. if it is not 'ecologically valid' (Bergman et al., 2009) within the reality of the game-world as presented to the player, then it needs to be clearly positioned within the ludic space. In order to do this, the sounds are deliberately characterized as non-realistic, granted iconic status through repetition and lack of spatialization, and often synthetic in quality (for example in Battlefield 4, the instruction notification, proximity notification, achievement unlock notification, deploy ready notification, and SALI sounds are all based on synthesized or electronic sources).

\section{The implications for immersion}

A player may wander around an environment (their sensory experience contributing to immersion), then have an encounter with an enemy (challenge driven immersion) before becoming involved with the narrative through a brief cut scene (narrative driver). ${ }^{20}$ They may become lost in the music of the cutscene (music instigated immersion) before being rudely pulled out of their immersive state by the inconsiderate interruption of a spouse or parent... Upon re-entering the game, the sensory experience once again immerses them before the next challenge begins (see Figure 18 below).

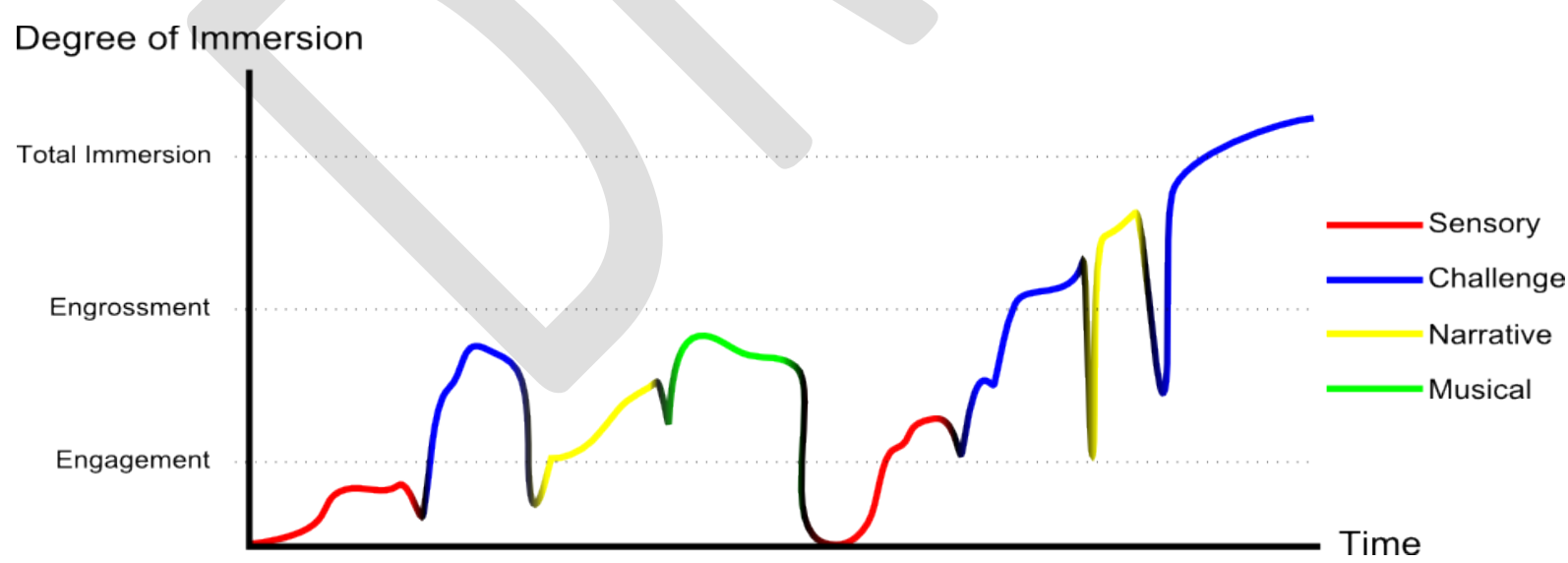

Figure 16: A hypothetical model of a player's immersive experience.

\footnotetext{
${ }^{19}$ Schema is 'mental representations of what we know and have come to expect about the world' (Bernstein, 2011).

20 The sensory, challenge based, and narrative immersions referred to here derive from Ermi and Mäyrä (2005).
} 
Understanding the apparent paradox of the authentic and inauthentic illustrates in a new way what has been recognized for some time, that players not only occupy different roles at different times when playing a game, but actually oscillate between different schemas and different drivers of immersion (Lindley and Sennersten, 2008). This is supported by Calleja's observation that since 'humans have a limited attentional capacity, devoting more conscious attention to one of the dimensions leaves less that can be invested in others' (Calleja, 2011: 45). ${ }^{21}$ Whilst there is no evidence to suggest that the inauthentic ego-ludic disrupts immersion during challenge based gameplay (as long as its ludic nature and function is clear), the presence of the ego-ludic when other immersive drivers are operating runs the risk of necessitating a schema, driver or dimension change, with the potential for a subsequent dip in immersion due to the cognitive load of enacting such a transition. A typical example of the potential for the ego-ludic to disrupt immersion might be where the presence of a trophy sound, or a notification that a friend is now online disrupts a narrative or musically immersive sequence. There is perhaps some evidence that this is understood on a design level in Battlefield 4 when we observe that the narrative cutscenes temporarily exclude the elements of ego-ludic audio and visual HUDs in sequences that are clearly differentiated from normal gameplay (Figure 19).

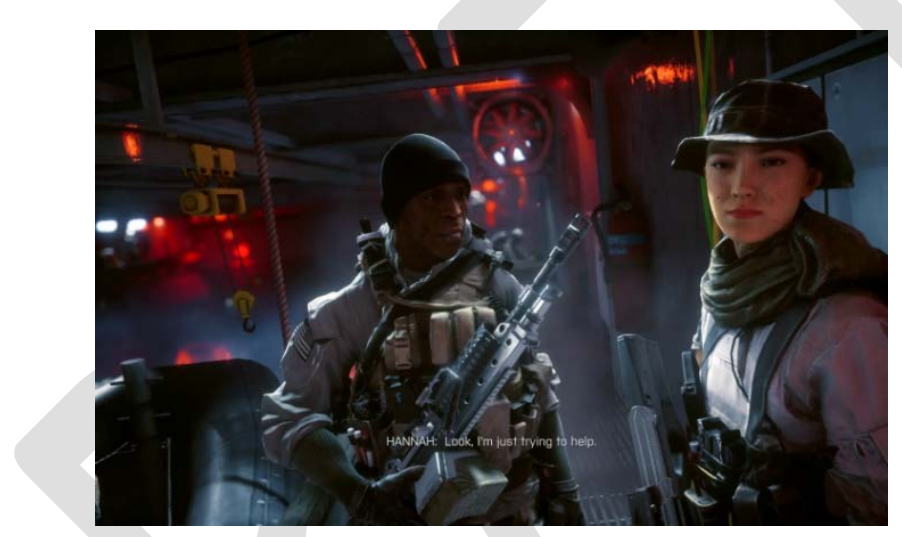

Figure 19: Illustrating the lack of ludic elements (HUDs) during narrative cutscenes.

\section{Conclusions}

The immersive authenticity of the Battlefield series is generated through reconstructing the reality, and perceived reality, of the physical world. It achieves this both through an obsessive attention to detail in the accuracy of its representations, and through the recognition that our notions of "real", particularly when it comes to war, are formed to a large extent by our exposure to media (the "mediated real"). The colorations or distortions produced by low fidelity media or recordings immerse the player in a perceived reality, whilst at the same time it is the low fidelity of sensory information available to the player that necessitates the presence of the deliberately unreal or inauthentic; the ego-ludic sounds required to fill these perceptual holes, enabling a mastery of the game. We have seen how players' acceptance of this paradox between the simultaneously authentic and inauthentic can be explained by their familiarity with gameplay schemas, but that the presence of unreal or inauthentic audio elements is only accepted when the drivers for immersion are challenge based, and the sounds have a clearly identified ludic role.

\footnotetext{
${ }^{21}$ Calleja's player involvement model refers to kinesthetic involvement, spatial involvement, shared involvement, narrative involvement, affective involvement and ludic involvement (2011).
} 


\section{Bibliography}

Aarseth, E.(2004), 'Genre Trouble: Narrativism and the Art of Simulation', in N. Wardrip-Fruin and P. Harrigan (eds), First Person: New Media as Story, Performance and Game. Massachusetts: MIT Press, pp. 45-55.

Activision (2013), Call of Duty: Ghosts [Console], California: Activision.

Beck, J. (2008), 'The Sounds of “Silence”: Dolby Stereo, Sound Design, and The Silence of the Lambs', in J. Beck and T. Grajeda (eds), Lowering the Boom: Critical Studies in Film Sound. Illinois: Illinois University Press, pp. 68-83.

Bergman, P., Sköld, A., Västfjäll, D., and Fransson, N. (2009), 'Perceptual and Emotional Categorization of Sound', Journal of the Acoustical Society America, 126: 6, pp. 3156-3167.

Bethesda Softworks (2011), The ElderScrolls V: Skyrim [PC], Maryland: Zenimax Media.

Beynon, S. (2013), PTSD and How Battlefield Potentially Saved My Life [Online]. Giantbomb. Available from: <http://www.giantbomb.com/profile/epicsteve/blog/ptsd-and-how-battlefield-potentially-savedmy-life/103621/> [Accessed 21 May 2014].

Broomhall, J. (2013), 'Heard About: Battlefield 4', Develop Magazine, December 2013, 145, p. 41.

Brown, E. and Cairns, P. (2004), 'A Grounded Investigation of Game Immersion', in CHI'04 Extended Abstracts on Human Factors in Computing Systems, pp. 1297-1300.

Calleja, G. (2011), In-Game: From Immersion to Incorporation, Massachusetts: MIT Press.

Chion, M. (1994), Audio Vision: Sound on Screen. New York: Columbia University Press.

(2009), Film: A Sound Art. Columbia: Columbia University Press.

(2010), Le son. Traité d'acoulogie. Paris: Armand Colin.

Collins, K. (2008), Game Sound: An Introduction to the History, Theory, and Practice of Video Game Music and Sound Design, Massachusetts: MIT Press.

---------- (2011), 'Making Gamers Cry: Mirror Neurons and Embodied Interaction with Game Sound', in Proceedings of the 6th Audio Mostly Conference: A Conference on Interaction with Sound, pp. 39-46.

(2013), Playing with Sound: A Theory of Interacting with Sound and Music in Video Games. Massachusetts: MIT Press.

Csíkszentmihályi, M., and Csíkszentmihályi, I. S. (1992) Optimal Experience: Psychological Studies of Flow in Consciousness, Cambridge: Cambridge University Press. 
Edsall, J. (2003), ‘Animation Blending: Achieving Inverse Kinematics and More’ [Online] Gamasutra, Available from <http://www.gamasutra.com/view/feature/3456/animation_blending_achieving_.php> [Accessed 02 May 2013].

Eidos Montreal (2011), Deus Ex: Human Revolution [PC]. Montreal: Square Enix.

Electronic Arts (2010), Battlefield: Bad Company 2 [Console]. California: Electronic Arts.

Electronic Arts (2011a), Battlefield 3 [PC]. California: Electronic Arts.

(2011b), Battlefield 3 - Is it real? - Trailer (HD) [Online video], 24 October. Available from: < https://www.youtube.com/watch?v=FlxX8DBMITE> [Accessed 21 May 2014].

(2012), Mass Effect 3 [PC]. California: Electronic Arts.

(2013), Battlefield 4 [PC]. California: Electronic Arts.

Ermi, L. and Mäyrä, F. (2005), 'Fundamental Components of the Gameplay Experience: Analysing Immersion', in: Changing Views: Worlds in Play. Selected Papers of the 2005 Digital Games Research Association's Second International Conference, pp. 15-27.

Fagerholt, E. and Lorentzon, M. (2009), Beyond the HUD: User Interfaces for Increased Player Immersion in FPS Games [MSc. Thesis], Chalmers University of Technology.

Gapper, M. (2014), ‘War Machines’, Edge Magazine, July 2014, 268, pp. 58-69.

Grimshaw, M. (2007), 'The Resonating Spaces of First-Person Shooter Games’, in Proceedings of The 5th International Conference on Game Design and Technology, Liverpool: Game Design and Technology Workshop.

Grimshaw, M. (2010), 'Player Relationships as Mediated Through Sound in Immersive Multi-player Computer Games’, Revista Comunicar, 17: 34, pp. 73-80. (2012), 'Sound and Immersion in Digital Games', in T. Pinch and K. Bijsterveld (eds), The Oxford Handbook of Sound Studies, New York: Oxford University Press, pp. 347-366.

Huber, D.M. and Runstein, R.E. (2010), Modern Recording Techniques, $7^{\text {th }}$ Ed., New York: Taylor \& Francis.

IO Interactive (2012), Hitman: Absolution [PC]. Copenhagen: Square Enix.

Jock, 2011. Bash 181: The Sound of Battlefield [Podcast] Available from:

$<$ http://bashandslash.com/index.php?option=com_content\&task=view\&id=1274\&Itemid=1 $>$ [Accessed 21 May 2014]. 
Jørgensen, K. (2011), 'Time for a New Terminology?: Diegetic and Non-Diegetic Sounds in Computer Games Revisited’, in M. Grimshaw (ed.), Game Sound Technology and Player Interaction: Concepts and Developments, Hershey: Information Science Reference, pp. 78-97.

(2012), 'Between the Game System and the Fictional World A Study of Computer Game Interfaces’, Games and Culture, 7: 2, pp. 142-163.

(2014), Gameworld Interfaces, Cambridge, Massachusetts: MIT Press.

Kassabian, A. (2013), 'The End of Diegesis As We Know It?’, in J. Richardson, C. Gorbman and C. Vernallis (eds), The Oxford Handbook of New Audiovisual Aesthetics, New York: Oxford University Press, pp. 89-106.

Liebe, M. (2013), 'Interactivity and Music in Computer Games’, in P. Moormann (ed.), Music and Game: Perspectives on a Popular Alliance. Wiesbaden: Springer, pp. 41-62.

Lindley, C.A. and Sennersten, C.C. (2008), 'Game Play Schemas: From Player Analysis to Adaptive Game Mechanics’, International Journal of Computer Games Technology 2008, pp. 1-7.

Minto, Ben (2011), Four Guns West. The Game Developers Conference, San Francisco. February 28 March 4.

Nacke, L.E., Stellmach, S., and Lindley, C.A. (2011), 'Electroencephalographic Assessment of Player Experience: A Pilot Study in Affective Ludology’, Simulation \& Gaming, 42: 5, pp. 632-655.

Nintendo (1985), Super Mario Bros. [Console]. Kyoto: Nintendo.

Poulsen, M. and Gatzidis, C. (2010), 'Understanding the Game: An Examination of Ludoliteracy’, in B. Meyer (ed.), Proceedings of the 4th European Conference on Games-Based Learning: ECGBL 2009, Reading: Academic Conferences Limited, pp. 316-324.

Przybylski, A. K., Rigby, C. S., and Ryan, R. M. (2010), 'A Motivational Model of Video Game Engagement', Review of General Psychology, 14/2, pp. 154-166.

Raghuvanshi, N., Snyder, J., Mehra, R., Lin, M. C., Govindaraju, N. K., 2010. Precomputed Wave Simulation for Real-Time Sound Propagation of Dynamic Sources in Complex Scenes. In: ACM Transactions on Graphics - Proceedings of ACM SIGGRAPH 2010. 29, 4.

Ryan, R.M., Rigby, C.S. and Przybylski, A. (2006), 'The Motivational Pull of Video Games: A SelfDetermination Theory Approach’, Motivation and Emotion 30: 4, pp. 344-360.

Saastamoinen Minto, M. (2013), The Road to Battlefield 4: Sounds of the Battlefield [Online]. SkyOkapi. Available from: <http://blogs.battlefield.com/2013/10/road-to-bf4-sounds-of-the-battlefield/> [Accessed 21 May 2014]. 
Schafer, R. M. (1994), Soundscape: Our Sonic Environment and the Tuning of the World, Rochester, United States: Destiny Books.

Skalski, P., and Whitbred, R. (2010), 'Image versus Sound: A Comparison of Formal Feature Effects on Presence and Video Game Enjoyment’, PsychNology Journal, 8: 1, pp. 67-84.

Stevens, R. and Raybould, D. (2011), The Game Audio Tutorial: A Practical Guide to Sound and Music for Interactive Games, San Francisco: Focal Press.

2014, 'Designing a Game for Music: Integrated Design Approaches for Ludic Music and Interactivity’, in K. Collins, B. Kapralos and H. Tessler (eds), The Oxford Handbook of Interactive Audio, New York: Oxford University Press, pp. 147-166.

Ubisoft (2013), Assassin’s Creed IV: Black Flag [PC]. Montreal: Ubisoft.

Ubisoft Montreal (2013), Tom Clancy’s Splinter Cell: Blacklist [PC]. Montreal: Ubisoft. (2012), Far Cry 3 [PC]. Montreal: Ubisoft.

Vachon, J. F. (2009), ‘Avoiding Tedium - Fighting Repetition in Game Audio’, in Audio Engineering Society Conference: 35th International Conference: Audio for Games.

Valve (2013), DOTA 2 [PC]. Washington: Valve Corporation. 